\title{
EWSR1/ERG Fusion Protein
}

National Cancer Institute

\section{Source}

National Cancer Institute. EWSR1/ERG Fusion Protein. NCI Thesaurus. Code C99212.

A fusion protein encoded by the EWSR1/ERG fusion gene. This protein is comprised of the transactivation domain of the RNA-binding protein EWS followed by the C-terminal domain of the transcriptional regulator ERG protein, which includes the ETS DNA binding domain. 